\title{
Co-culturing with hypoxia pre-conditioned mesenchymal stem cells as a new strategy for the prevention of irradiation-induced fibroblast-to-myofibroblast transition
}

\author{
LEI ZHUANG $^{1 *}$, WENZHENG XIA ${ }^{2,3^{*}}$ and MENG HOU ${ }^{4}$
}

\begin{abstract}
Departments of ${ }^{1}$ Hepatobiliary Surgery and ${ }^{2}$ Neurosurgery, First Affiliated Hospital, Wenzhou Medical University, Wenzhou, Zhejiang 325000; ${ }^{3}$ Department of Neurosurgery, Xinhua Hospital Affiliated to Shanghai Jiaotong University

School of Medicine, Shanghai 200030; ${ }^{4}$ Department of Radiation Oncology, First Affiliated Hospital, Wenzhou Medical University, Wenzhou, Zhejiang 325000, P.R. China
\end{abstract}

Received April 20, 2019; Accepted July 26, 2019

DOI: $10.3892 /$ or.2019.7293

\begin{abstract}
Cardiac fibrosis is a pathological consequence of radiation-induced fibroblast proliferation and fibroblast-to-myofibroblast transition (FMT). Mesenchymal stem cell (MSC) transplantation has been revealed to be an effective treatment strategy to inhibit cardiac fibrosis. We identified a novel MSC-driven mechanism that inhibited cardiac fibrosis, via the regulation of multiple fibrogenic pathways. Hypoxia pre-conditioned MSCs (MSCs ${ }^{\text {Hypoxia }}$ ) were co-cultured with fibroblasts using a Transwell system. Radiation-induced fibroblast proliferation was assessed using an MTT assay, and FMT was confirmed by assessing the mRNA levels of various markers of fibrosis, including type I collagen (Col1) and alpha smooth muscle actin ( $\alpha$-SMA). $\alpha$-SMA expression was also confirmed via immunocytochemistry. The expression levels of Smad7 and Smad3 were detected by western blotting, and Smad7 was silenced using small interfering RNAs. The levels of oxidative stress following radiation were assessed by the detection of reactive oxygen species (ROS) and the activity of superoxide dismutase (SOD), malondialdehyde (MDA), and 4-hydroxynonenal (HNE). It was revealed that co-culturing with MSCs ${ }^{\text {Hypoxia }}$ could inhibit fibroblast proliferation and FMT. In addition, the present results indicated that MSCs are necessary and sufficient for the inhibition of fibroblast proliferation and FMT by functionally targeting TGF- $\beta 1 / \mathrm{Smad} 7 / \mathrm{Smad} 3$ signaling via the release of hepatocyte
\end{abstract}

Correspondence to: Dr Meng Hou, Department of Radiation Oncology, First Affiliated Hospital, Wenzhou Medical University, 2 Fuxue Lane, Wenzhou, Zhejiang 325000, P.R. China E-mail:244517813@qq.com

*Contributed equally

Key words: mesenchymal stem cells, radiation-related cardiac fibrosis, hepatocyte growth factor, TGF- $\beta 1 /$ Smad signaling pathway, oxidative stress growth factor (HGF). Furthermore, it was observed that MSCs inhibited fibrosis by modulating oxidative stress. Co-culturing with $\mathrm{MSCs}^{\text {Hypoxia }}$ alleviated fibroblast proliferation and FMT via the TGF- $\beta 1 /$ Smad7/Smad3 pathway. MSCs may represent a novel therapeutic approach for the treatment of radiation-related cardiac fibrosis.

\section{Introduction}

Epidemiological studies have revealed an increased risk of cardiovascular disease associated with high local doses of ionizing radiation to the heart. This can be observed in patients who have received thoracic radiotherapy treatment for breast cancer, Hodgkin's disease, or childhood cancers $(1,2)$. A significant increase in mortality from cardiovascular disease has been reported among patients treated by radiotherapy $(3,4)$. Typically, cardiac symptoms appear late, sometimes decades after exposure to radiation, and include increased infiltration of inflammatory cells and fibrosis of the myocardium, especially after receiving high radiation doses (5). In addition to vascular abnormalities, recent studies have emphasized cardiac fibrosis as a major causal factor for radiation-induced heart disease (6), a condition that is accompanied by an accumulation of fibroblasts and fibroblast-to-myofibroblast transition (FMT) (7).

One area of interest is the potential for mesenchymal stem cells (MSCs) to repair injured cardiac tissue. MSCs possess the capacity for self-renewal, multipotency, and cytokine secretion $(8,9)$, characteristics which render them ideal for tissue repair or regeneration applications $(10,11)$. Recent studies have indicated that MSCs could potentially exert anti-fibrotic effects in the context of cardiac disease, which may allow for repair of the damaged myocardium (12). Previous studies have revealed that MSCs pre-treated with hypoxia secrete a variety of cytokines such as vascular endothelial growth factor, hepatocyte growth factor (HGF), basic fibroblast growth factor, interleukin-10, as well as others, which act to inhibit cardiac fibrosis $(13,14)$.

TGF- $\beta$ is considered a 'master' cytokine/growth factor produced within injured or diseased tissues, where it activates 
fibroblasts and facilitates the production of extracellular matrix (ECM), leading to tissue fibrosis (15). TGF- $\beta$ binds a heterodimeric receptor in the plasma membrane consisting of the TGF- $\beta$ type I and type II half-receptors, which together induce phosphorylation of Smad3 transcription factors in the canonical signaling pathway (16). Smad7 acts as an inhibitor of TGF- $\beta$ signaling by interacting with the TGF- $\beta$ type I receptor, preventing the phosphorylation and activation of Smad3 (17). It has been reported that Smad7 can block TGF- $\beta$-induced fibroblast accumulation, inhibiting FMT, which can further inhibit fibrosis (18).

The pathogenesis of cardiac fibrosis involves alterations in the cellular and neuro-humoral environments, leading to changes in fibroblast activity and ECM turnover $(19,20)$. The oxidative stress that is induced by radiation is further increased in response to mechanical and metabolic stress, triggering increased activation and proliferation of fibroblasts, which in turn leads to tissue fibrosis $(21,22)$. Notably, abundant data have revealed that MSCs have a strong capacity to suppress oxidative stress, leading to an inhibition of cardiac fibrosis and protective effects (23).

Based on the aforementioned observation, it was hypothesized that hypoxia pre-conditioned MSCs would be superior to MSCs or hypoxia in isolation in inhibiting radiation-induced cardiac fibrosis.

\section{Materials and methods}

Cell culture. Normal human cardiac fibroblasts (HCFs) were purchased from Cell Applications, Inc. Fibroblasts were maintained in low glucose Dulbecco's modified Eagle's media (DMEM) supplemented with $10 \%$ fetal bovine serum (FBS), $1 \%$ penicillin-streptomycin (Beyotime Institute of Biotechnology), and $100 \mu \mathrm{g} / \mathrm{ml}$ streptomycin (Life Technologies; Thermo Fisher Scientific, Inc.).

Bone marrow-derived human MSCs (BM-hMSCs) were purchased from ATCC, and seeded at 5,000 cells $/ \mathrm{cm}^{2}$ in DMEM-F12 growth media with 1\% Glutamax (Sigma-Aldrich; Merck KGaA) and $1 \%$ penicillin-streptomycin, and were grown to $80-85 \%$ confluency.

Cell treatment. In order to induce radiation exposure, $1 \times 10^{5}$ fibroblasts grown in 6-well plates were irradiated in a $15 \times 15 \mathrm{~cm}^{2}$ square field with 5 Gy (6-MeV electron rays; current, $6 \mathrm{~A}$; dose rate, 2 Gy/min) (X RAD 225; PRECISION X-ray, Inc.).

A Transwell system was used to prevent direct contact between hMSCs and HCFs. hMSCs and HCFs were placed in the upper and lower layers of the Transwell plate, respectively, at a density of $1 \times 10^{6}$ cells/well.

Hypoxia pre-conditioning was performed by incubating MSCs for $30 \mathrm{~min}$ in serum-free media in a controlled atmosphere (anaerobic chamber) glove box (855-AC; Plas Labs, Inc.) to scavenge for free oxygen.

To block the HGF function, we used anti-HGF antibody to neutralize the HGF. The anti-HGF antibody was added one hour before cell treatment, and this antibody was purchased from Sigma Aldrich; Merck KGaA (product no. H0652).

Cell proliferation assay. Fibroblast proliferation was determined using an MTT Cell Proliferation Assay kit (ATCC) according to the manufacturer's instructions. Briefly, $300 \mu \mathrm{l}$ of MTT reagent was added to each well $\left(1 \times 10^{5}\right.$ cells $) 3 \mathrm{~h}$ prior to harvesting. Absorbance at $540 \mathrm{~nm}$ was recorded using an enzyme-linked immunosorbent assay (ELISA) plate reader. Three repeats were performed.

Quantitative reverse transcription polymerase chain reaction ( $q R T-P C R)$. Total RNA was isolated from cardiac fibroblasts with TRIzol (Ambion; ThermoFisher Scientific, Inc.). An ultraviolet spectrophotometer was used to quantify the RNA. cDNA was synthesized from $1 \mu \mathrm{g}$ of total RNA using Superscript II reverse transcriptase (Invitrogen), as per the manufacturer's protocol. The qPCR was carried out using the Fast Start Universal SYBR Master and a fluorescence quantitative PCR system. RT-PCR was conducted as previously described (24). The relative expression levels were calculated with the $2^{-\Delta \Delta \mathrm{Cq}}$ method (25), using GAPDH as the internal control. Primer sets (Invitrogen; ThermoFisher Scientific, Inc.) used are listed in Table I.

Western blot analysis. Cardiac fibroblasts were lysed with ice-cold lysis buffer (Beyotime Institute of Biotechnology, Haimen, China) to obtain total protein. Protein samples $(20 \mu \mathrm{g})$ were quantified using BCA Protein Assay kit, and separated by $10 \%$ SDS-PAGE, and then the proteins were transferred to polyvinylidene difluoride membranes (EMD Millipore). Then, the membranes were blocked with $5 \%$ milk in Tris-buffered saline, followed by incubation with the appropriate primary antibodies: Smad7 (1:1,000; product code ab90086; Abcam); Smad3 (1:1,000; product no. 9513); p-Smad3 (1:1,000; product no. 9520$)$; and $\beta$-actin, (1:2,000; product no. 4970; all from CST) overnight at $4^{\circ} \mathrm{C}$. Membranes were then incubated with horseradish peroxidase-conjugated secondary antibodies (1:2,000 dilution; cat. no. 7074; from Cell Signaling Technology, Danvers, MA, USA), and developed using High Sensitivity ECL Substrate kit (product code ab133406; Abcam). The stained protein bands were visualized using Bio-Rad ChemiDoc XRS equipment, and quantified and analyzed using Quantity One software. Three repeats were performed.

Immunofluorescence. After treatment, cardiac fibroblasts were seeded in cell culture dishes, fixed in $4 \%$ paraformaldehyde, and permeabilized with $0.1 \%$ Triton $\mathrm{X}-100$, followed by blocking in $3 \%$ bovine serum albumin (BSA), washed by phosphate-buffered saline (PBS). They were then immunolabeled with specific primary antibodies [alpha smooth muscle actin ( $\alpha$-SMA); 1:200; product code ab32575; Abcam] overnight at $4^{\circ} \mathrm{C}$. After rinsing, the cells were incubated with the corresponding FITC-conjugated secondary antibodies (1:250) (product code ab7086; Abcam) in $1 \%$ BSA for $1 \mathrm{~h}$ at $37^{\circ} \mathrm{C}$. Nuclei were stained with DAPI for $5 \mathrm{~min}$ at room temperature. Fluorescence was detected under a fluorescence microscope.

ELISA. The concentration of HGF in the supernatant was determined using an HGF Human ELISA kit (Abcam). Samples from each group (groups as follows: Control; Radiation; Radiation $+\mathrm{MSCs}^{\text {Hypoxia }}$; Radiation $+\mathrm{MSCs}^{\text {Normoxia }}$ ) were collected in sterile tubes and centrifuged at $1,500 \mathrm{x} \mathrm{g}$ for 15 min to obtain supernatants. The supernatants were analyzed according to the manufacturer's instructions. 
Table I. Primer sequences.

\begin{tabular}{ll}
\hline Genes & \multicolumn{1}{c}{ Sequences } \\
\hline Col1 & F: 5'-CCTGGAAAGAATGGAGATGATG-3' \\
& R: 5'-ATCCAAACCACTGAAACCTCTG-3' \\
$\alpha$-SMA & F: 5'-TGACAATGGCTCTGGGCTCTGTAA-3' \\
& R: 5'-TTCGTCACCCACGTAGCTGTCTTT-3' \\
HGF & F: 5'-ACCCTGGTGTTTCACAAGCA-3' \\
& R: 5'-GCAAGAATTTGTGCCGGTGT-3' \\
TGF- $\beta 1$ & F: 5'-GGACACCAACTATTGCTTCAG-3' \\
& R: 5'-TCCAGACTCCAAATGTAG-3 \\
GAPDH & F: 5'-GGGCTGCTTTTAACTCTGGT-3' \\
& R: 5'-GCAGGTTTTTCTAGACGG-3'
\end{tabular}

Col1, type I collagen; $\alpha$-SMA, $\alpha$-smooth muscle actin; HGF, hepatocyte growth factor; $\mathrm{F}$, forward; $\mathrm{R}$, reverse.

Small interfering (si)RNA transfection. siRNAs were used to knock down Smad7 in fibroblasts. A non-targeting siRNA was used as a negative control (Invitrogen; ThermoFisher Scientific, Inc.). The target sequences were as follows: Smad7, GCAGCCTAACCAGACCTTT; Control, AACCTGCGG GAAGAAGTGG. Transfection efficiency was detected by western blotting.

Microarray. Cardiac fibroblasts irradiated were immediately lysed in $500 \mu 1$ TRIzol (Thermo Fisher Scientific, Inc.) and stored at $-80^{\circ} \mathrm{C}$ before purification by a standard phenolchloroform extraction protocol using the RNAqueous Micro kit (Thermo Fisher Scientific, Inc.). The transcriptome was analyzed by microarray using an Affymetrix human array (Thermo Fisher Scientific, Inc.) and normalized based upon quantiles.

Measurement of reactive oxygen species (ROS) production. Cells were detached from culture plates using $0.25 \%$ trypsin-EDTA, collected in 5-ml round-bottom polystyrene tubes, and washed with $1 \mathrm{X}$ Wash Buffer (PBS). The cell suspension was centrifuged for $5 \mathrm{~min}$ at $400 \mathrm{x}$ g at room temperature, and the supernatant was discarded. The cell pellet was resuspended in $500 \mu \mathrm{l}$ of ROS/Superoxide Detection Solution. Cells were incubated for $30 \mathrm{~min}$ at $37^{\circ} \mathrm{C}$ in the dark. Data were acquired on a FACScan instrument (BD Biosciences) and analyzed using CellQuest software (BD Biosciences).

Superoxide dismutase (SOD) activity. SOD activity in cells was determined using a colorimetric assay kit (Abcam), according to the manufacturer's instructions. Briefly, protein was isolated from cells using lysis buffer (supplied by the kit), and SOD activity was measured using $10 \mu \mathrm{g}$ of total protein extract. Absorbance was measured at $450 \mathrm{~nm}$.

Lipid peroxidation assay. Lipid peroxidation was measured using an assay kit (Abcam) that measures the formation of malondialdehyde (MDA), according to the manufacturer's instructions. Briefly, fibroblasts $\left(1 \times 10^{6}\right.$ cells $)$ were homogenized on ice in $300 \mu \mathrm{l}$ of MDA lysis buffer (containing
$3 \mu \mathrm{l}$ of 100X butylated hydroxytoluene, supplied by the kit), then centrifuged $(13,000 \times \mathrm{g}$ for $10 \mathrm{~min})$ to remove insoluble material. The supernatant $(200 \mu \mathrm{l})$ was added to $600 \mu \mathrm{l}$ of thiobarbituric acid and incubated at $95^{\circ} \mathrm{C}$ for $60 \mathrm{~min}$. Samples were then cooled to room temperature in an ice bath for $10 \mathrm{~min}$, and the absorbance at $532 \mathrm{~nm}$ was measured on a spectrophotometer.

Determination of 4-hydroxynonenal (4-HNE) levels. The level of 4-HNE was evaluated using commercially available Lipid Peroxidation (4-HNE) Assay kit (product code ab238538), according to the manufacturer's instructions.

Statistical analysis. Data are expressed as the mean \pm standard deviation (SD). Differences between groups were tested using a one-way analysis of variance followed by Tukey's multiple comparisons test, and comparisons between two groups were evaluated using a Student's t-test. Analyses were performed using the SPSS package v19.0 (SPSS, Inc.). $\mathrm{P}<0.05$ was considered to indicate a statistically significant difference.

\section{Results}

Effects of hypoxia-treated MSCs (MSCs $\left.{ }^{\text {Hypoxia }}\right)$ on radiation-induced fibroblast proliferation and FMT. Proliferating fibroblasts and FMT-derived myofibroblasts are the major source of collagen and other ECM proteins during pathological matrix remodeling (26). When irradiated fibroblasts were co-cultured with MSCs ${ }^{\text {Hypoxia }}$, fibroblasts exhibited a lower proliferation rates compared to those that were not exposed to MSCs. Additionally, normoxia-conditioned MSCs (MSCs $^{\text {Normoxia }}$ ) resulted in no inhibition of fibroblast proliferation, compared with the radiation group (Fig. 1A).

In order to investigate whether MSCs ${ }^{\text {Hypoxia }}$ inhibited FMT, the mRNA levels of various markers of fibrosis including type I collagen (Col1) and $\alpha$-SMA were measured. It was revealed that irradiated fibroblasts exhibited a significant increase in the levels of Col1 and $\alpha$-SMA mRNA, whereas co-culturing with $\mathrm{MSCs}^{\text {Hypoxia }}$ reversed this increase (Fig. 1B and $C$ ). In addition, fluorescence staining revealed increased $\alpha$-SMA staining in irradiated fibroblasts compared to those co-cultured with MSCs ${ }^{\text {Hypoxia }}$. No increase in $\alpha$-SMA expression was observed in irradiated fibroblasts co-cultured with $\mathrm{MSCs}^{\text {Normoxia }}$ (Fig. 1D).

Involvement of $\mathrm{HGF}$ in MSC $\mathrm{C}^{\text {Hypoxia }}$-driven inhibition of irradiation-induced fibroblast proliferation and FMT. Since MSCs obtain cytoprotection through their paracrine function, it was explored whether paracrine signaling was involved in the observed anti-fibrotic effects of MSCs ${ }^{\text {Hypoxia }}$. An ELISA was conducted to examine the release of HGF, and the results revealed that $\mathrm{MSCs}^{\text {Hypoxia }}$ released more $\mathrm{HGF}$ compared to MSCs ${ }^{\text {Normoxia }}$ (Fig. 2A). However, the levels of HGF mRNA did not differ between fibroblasts co-cultured with MSCs ${ }^{\text {Hypoxia }}$ and those co-cultured with MSCs ${ }^{\text {Normoxia }}$ (Fig. 2B).

To confirm whether MSC-derived HGF inhibited fibroblast proliferation and radiation-induced FMT, a neutralizing HGF antibody was used to neutralize the HGF protein. As revealed in Fig. 2C, radiation induced the proliferation of fibroblasts, and co-culturing with $\mathrm{MSCs}^{\text {Hypoxia }}$ decreased their proliferation. 

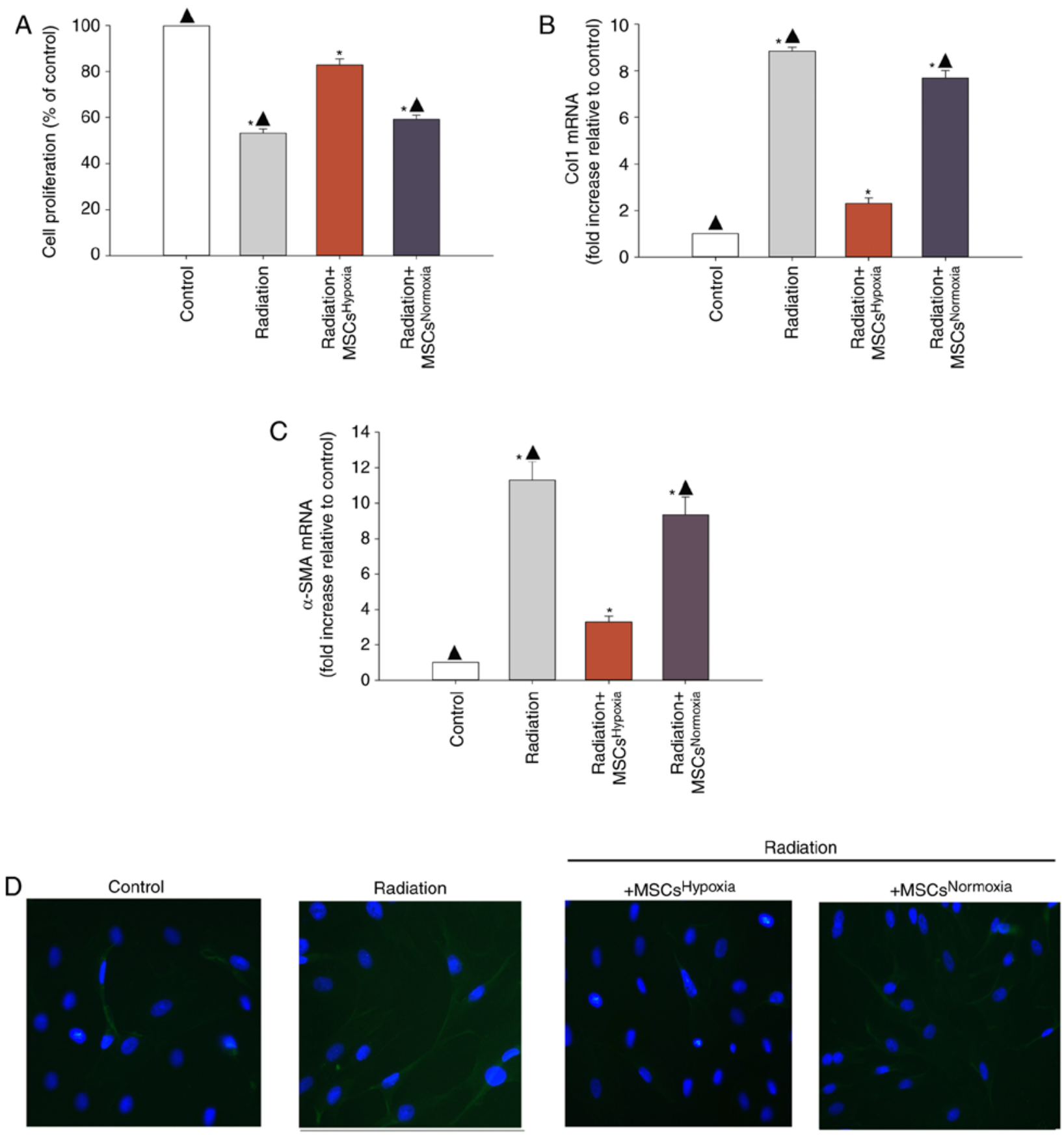

Figure 1. Effects of MSCs ${ }^{\text {Hypoxia }}$ on radiation-induced fibroblast proliferation and FMT. The following conditions were assessed: Fibroblasts alone, fibroblasts treated with radiation, and fibroblasts co-cultured with $\mathrm{MSCs}^{\mathrm{Hypoxia}}$ or $\mathrm{MSCs}^{\text {Normoxia }}$ in the presence of radiation. (A) Proliferation growth curves as determined by an MTT assay. (B and C) Coll and $\alpha$-SMA mRNA levels analyzed by RT-qPCR. (D) Expression of $\alpha$-SMA was assessed by immunofluorescence staining. Each column represents the mean \pm SD of three independent experiments; ${ }^{\prime} \mathrm{P}<0.05$ vs. the Control; ${ }^{\wedge} \mathrm{P}<0.05$ vs. Radiation $+\mathrm{MSCs}^{\mathrm{Hyp}}{ }^{\mathrm{A} x i a}$. MSCs, mesenchymal stem cells; FMT, fibroblast-to-myofibroblast transition; Col1, type I collagen; $\alpha$-SMA, $\alpha$-smooth muscle actin.

The addition of the anti-HGF antibody diminished the inhibitory effect of MSCs ${ }^{\text {Hypoxia }}$ on fibroblast proliferation. Moreover, the ability of $\mathrm{MSCs}^{\text {Hypoxia }}$ co-culture to reduce the radiation-induced increase in of Coll and $\alpha$-SMA mRNA levels was also impaired by the addition of the anti-HGF antibody (Fig. 2D and E). Additionally, the anti-HGF antibody abolished the inhibitory effect of $\mathrm{MSCs}^{\text {Hypoxia }}$ on $\alpha$-SMA protein expression in fibroblasts (Fig. 2F).

Identification of TGF- $\beta 1$ as a modulator of radiation-induced fibroblast proliferation and FMT. Microarray analysis was conducted to compare gene expression between fibroblasts treated or not treated with radiation (Fig. 3A). Genes with a $\geq 1.5$-fold increase in expression were considered upregulated. It was revealed that TGF- $\beta 1$ expression was increased upon exposure to radiation. Co-culture with $\mathrm{MSCs}^{\text {Hypoxia }}$ decreased the radiation-induced expression of TGF- $\beta 1$, while the addition of the anti-HGF antibody increased the expression of TGF- $\beta 1$ (Fig. 3B).

To investigate the effect of TGF- $\beta 1$ on radiation-induced fibroblast proliferation and FMT, recombinant TGF- $\beta 1$ was added to fibroblasts co-cultured with $\mathrm{MSCs}^{\text {Hypoxia }}$. The addition 

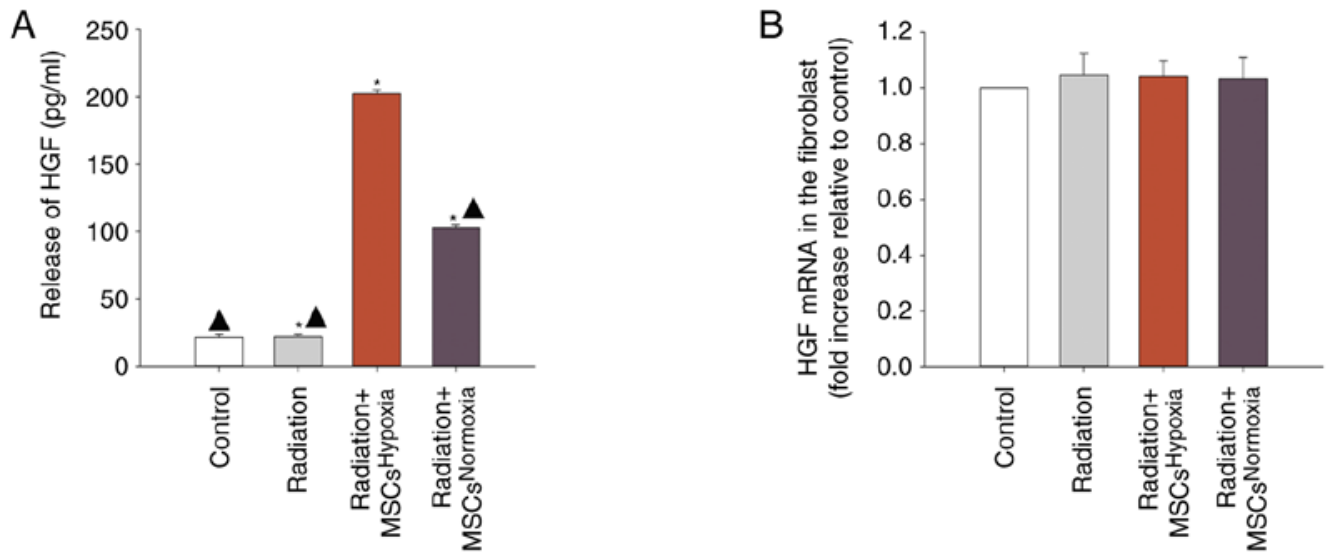
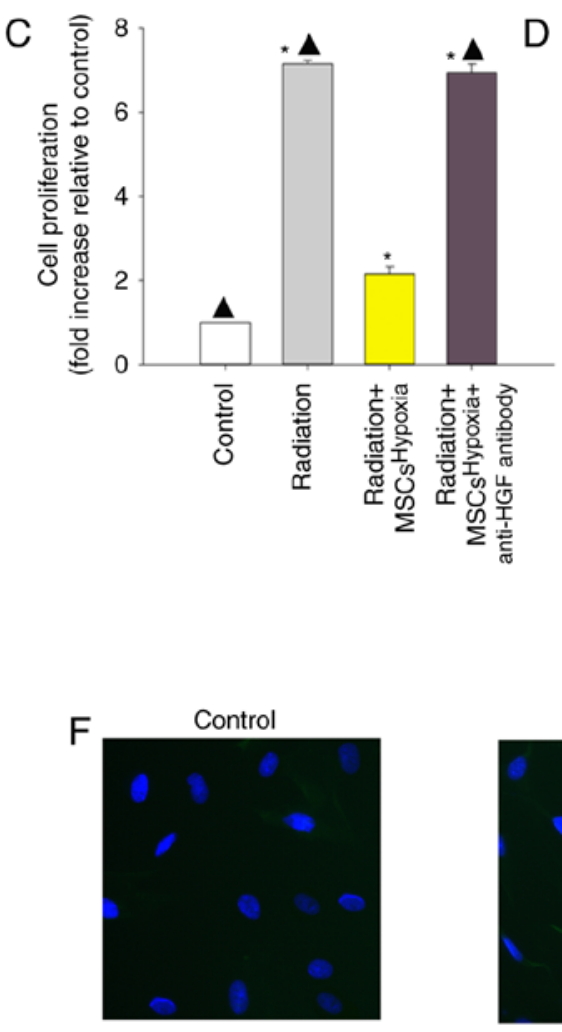
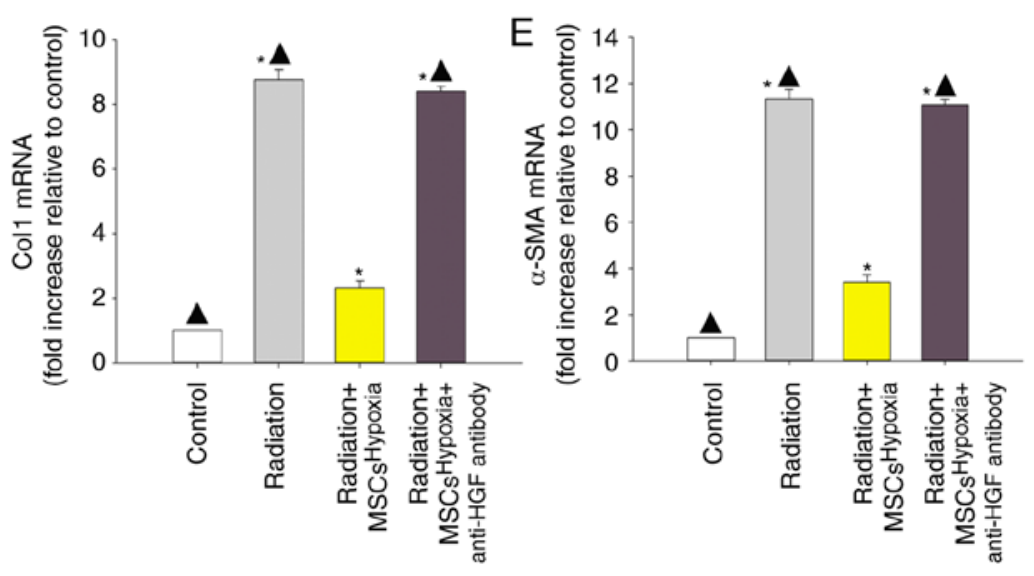
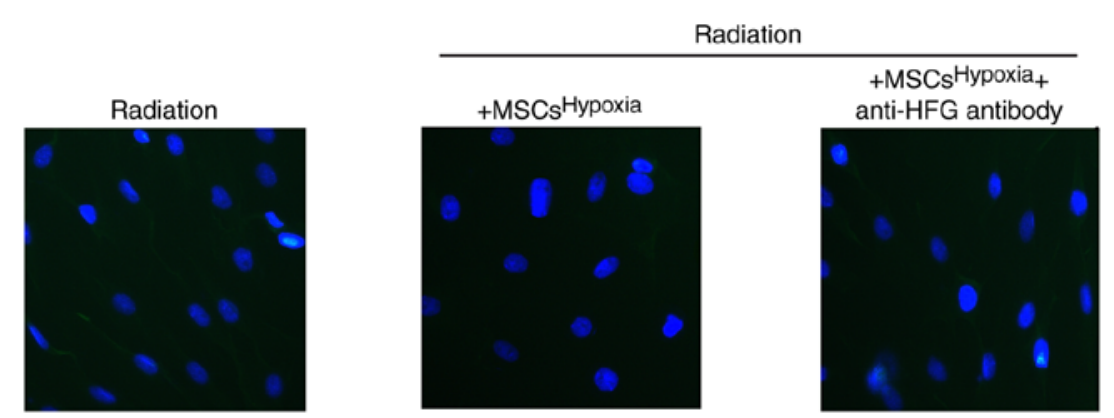

Figure 2. Involvement of HGF in MSCs ${ }^{\text {Hypoxia }}$-driven inhibition of fibroblast proliferation and radiation-induced FMT. To explore the role of the anti-fibrotic effect of MSCs ${ }^{\text {Hypoxia }}$ on radiation-treated fibroblast cells, a Transwell co-culture system was used. (A) ELISA measuring the release of HGF into the condition media of fibroblasts, fibroblasts treated with radiation, and fibroblasts co-cultured with MSCs ${ }^{\text {Hypoxia }}$ or MSCs $^{\text {Normoxia }}$ in the presence of radiation. (B) HGF mRNA levels in fibroblasts, fibroblasts treated with radiation, and fibroblasts co-cultured with MSCs ${ }^{\text {Hypoxia }}$ or MSCs $^{\text {Normoxia }}$ in the presence of radiation were analyzed by RT-qPCR. Each column represents the mean \pm SD from three independent experiments; ${ }^{*} \mathrm{P}<0.05$ vs. the Control; ${ }^{\wedge} \mathrm{P}<0.05$ vs. Radiation $+\mathrm{MSCs}{ }^{\text {Hypoxia }}$. In

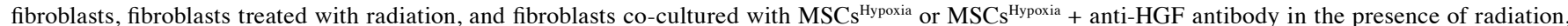
(C) proliferation growth curves were determined using an MTT assay. (D and E) Coll and $\alpha$-SMA mRNA levels as analyzed by RT-qPCR. (F) Expression of $\alpha$-SMA was measured using immunofluorescence staining. Each column represents the mean \pm SD from three independent experiments; ${ }^{*} \mathrm{P}<0.05$ vs. the Control; ${ }^{\wedge} \mathrm{P}<0.05$ vs. Radiation $+\mathrm{MSCs}^{\text {Hypoxia }}$. HGF, hepatocyte growth factor; MSCs, mesenchymal stem cells; FMT, fibroblast-to-myofibroblast transition; Coll, type I collagen; $\alpha$-SMA, $\alpha$-smooth muscle actin.

of recombinant TGF- $\beta 1$ not only led to a recovery of the impaired fibroblast proliferation induced by the $\mathrm{MSCs}^{\text {Hypoxia }}$ (Fig. 3C), but also increased the mRNA levels of Coll and $\alpha$-SMA, which were inhibited by co-culture with MSCs ${ }^{\text {Hypoxia }}$ (Fig. 3D and E).

Co-culturing with MSCs Hypoxia functionally targets TGF- $\beta 1 /$ Smad signaling to inhibit fibroblast proliferation and $F M T$. TGF- $\beta 1 /$ Smad signaling is a key pathway involved in FMT and fibrosis (27). Therefore, whether co-culturing with
MSCs ${ }^{\text {Hypoxia }}$ inhibited TGF- $\beta 1 /$ Smad signaling to block FMT in fibroblasts, was investigated. As revealed in Fig. 4A-D, radiation was associated with a decrease in Smad7 levels and an increase in p-Smad3 levels in fibroblasts. Moreover, co-culturing with $\mathrm{MSCs}^{\text {Hypoxia }}$ prevented the radiation-induced decrease in Smad7 levels, and inhibited the increase in p-Smad3 levels, in fibroblasts. The addition of the anti-HGF antibody or recombinant TGF- $\beta 1$ impaired the inhibition of MSCs ${ }^{\text {Hypoxia }}$ on TGF- $\beta$-induced phospho-Smad3, and impaired the expression of Smad7. 


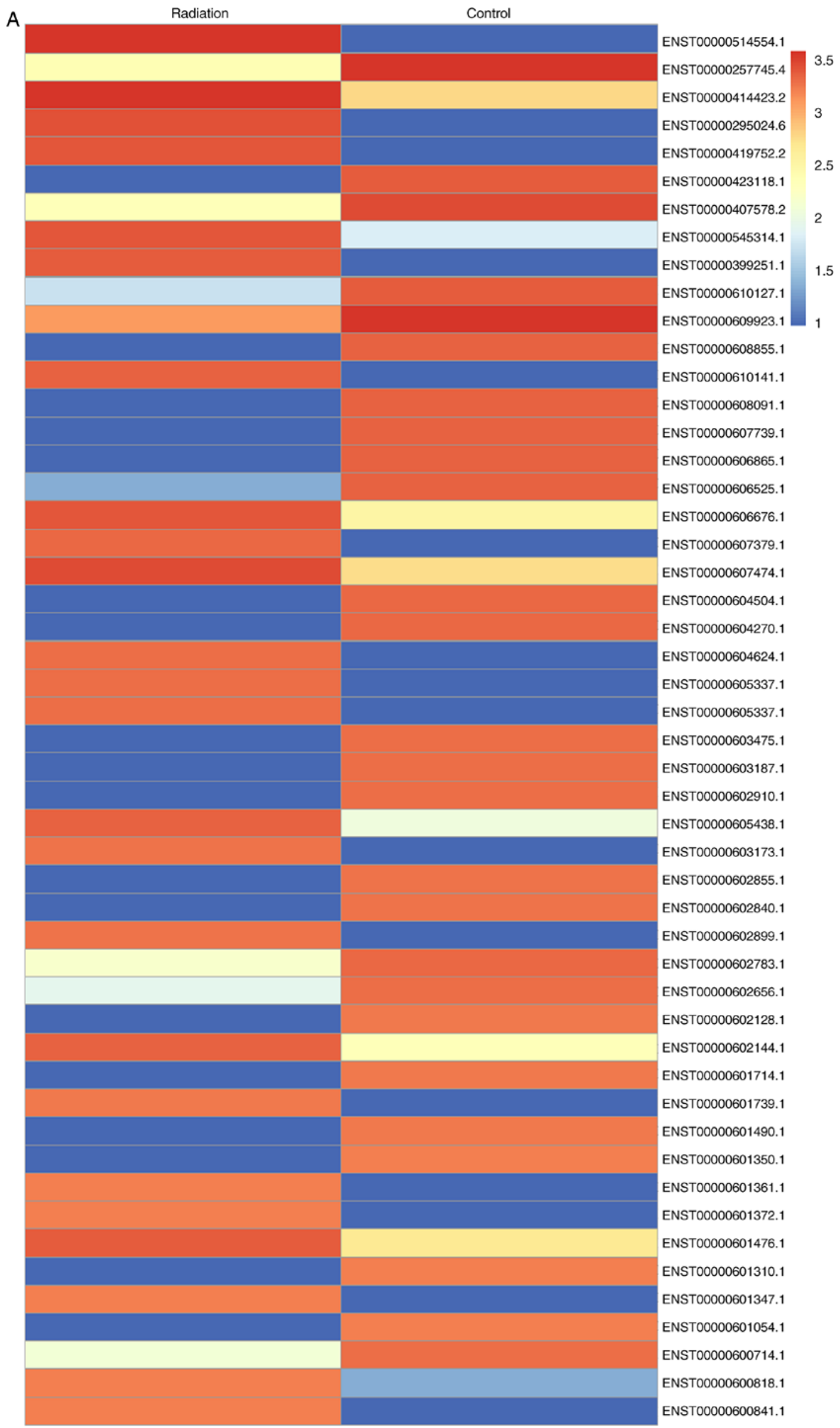

Figure 3. Identification of TGF- $\beta 1$ as a modulator of radiation-induced fibroblast proliferation and FMT. (A) Heat map of RNAs differentially regulated by radiation in fibroblasts. 'Red' indicates upregulation, and 'blue' indicates downregulation. 

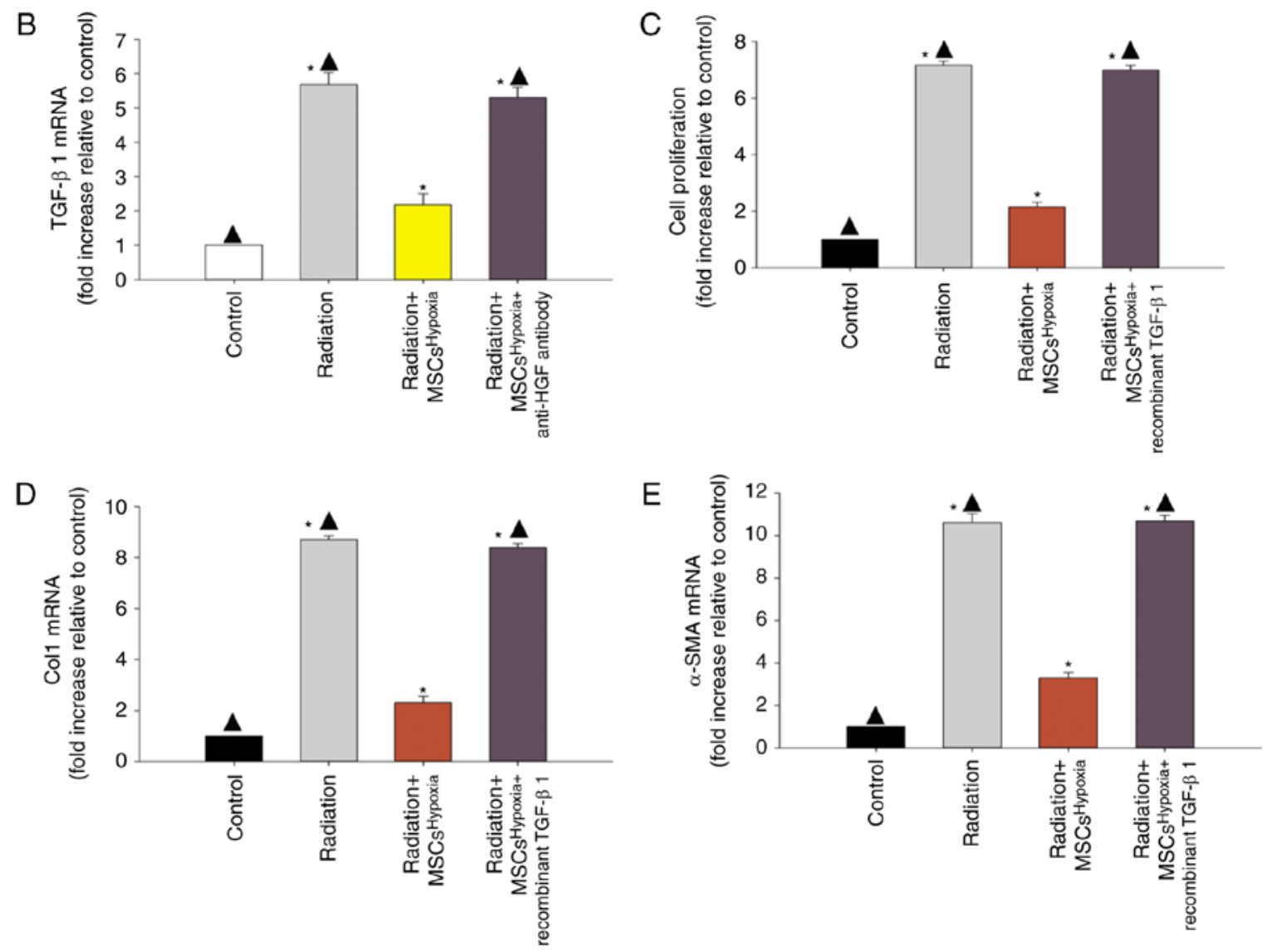

Figure 3. Continued. (B) RT-qPCR validation of differentially regulated RNAs in fibroblasts, fibroblasts treated with radiation, and fibroblasts co-cultured with MSCs ${ }^{\text {Hypoxia }}$ or MSCs ${ }^{\text {Hypoxia }}+$ anti-HGF antibody in the presence of radiation. ${ }^{*} \mathrm{P}<0.05$ vs. the Control; ${ }^{\boldsymbol{}}{ }^{\mathrm{P}}<0.05$ vs. Radiation $+\mathrm{MSCs}^{\text {Hypoxia }}$. In fibroblasts, fibroblasts treated with radiation, and fibroblasts co-cultured with MSCs ${ }^{\text {Hypoxia }}$ or MSCs ${ }^{\text {Hypoxia }}+$ recombinant TGF- $\beta 1$ in the presence of radiation, (C) proliferation growth curves were determined using an MTT assay. (D and E) Coll and $\alpha$-SMA mRNA levels as analyzed by RT-qPCR. Each column represents the mean \pm SD from three independent experiments; ${ }^{*} \mathrm{P}<0.05$ vs. the Control; ${ }^{\wedge} \mathrm{P}<0.05$ vs. Radiation + MSCs ${ }^{\text {Hypoxia }}$. FMT, fibroblast-to-myofibroblast transition; MSCs, mesenchymal stem cells; HGF, hepatocyte growth factor; Col1, type I collagen; $\alpha$-SMA, $\alpha$-smooth muscle actin.

To further confirm the role of TGF- $\beta 1 /$ Smad signaling in FMT, fibroblasts were transfected with siRNA-Smad7 or a non-targeting RNA as control. As revealed in Fig. 4E and F, fibroblasts that received siRNA-Smad7 exhibited decreased expression of the Smad7 protein, as assessed by western blotting. Functionally, silencing of Smad7 reversed the inhibitory effect of MSCs ${ }^{\text {Hypoxia }}$ on fibroblast proliferation (Fig. 5A) and on the mRNA levels of Coll and $\alpha$-SMA (Fig. 5B and C). As revealed in Fig. 5D, fibroblasts with silenced Smad7 that were co-cultured with MSCs ${ }^{\text {Hypoxia }}$ still exhibited strong expression of the $\alpha$-SMA protein, as assessed by immunofluorescence, indicating that TGF- $\beta 1 / \mathrm{Smad}$ signaling is a key pathway involved in FMT and fibrosis.

MSC Hypoxia co-culturing attenuates radiation-induced oxidative stress in fibroblasts. Oxidative stress drives the progression of FMT (28). A marked increase in the generation of ROS (Fig. 6A and B), reduced SOD activity (Fig. 6C), and increased levels of lipid peroxides (MDA and 4-HNE; Fig. 6D and E) were observed in radiation-treated fibroblasts. However, these changes were attenuated when fibroblasts were co-cultured with MSCs ${ }^{\text {Hypoxia }}$. The attenuation of oxidative stress induced by MSCs ${ }^{\text {Hypoxia }}$ was significantly suppressed when fibroblasts were treated with the anti-HGF antibody, recombinant TGF- $\beta 1$, or siRNA-Smad7.

\section{Discussion}

Radiation therapy, used during treatment for various types of cancer, is associated with an increased and dose-dependent risk of delayed-onset heart disease (29). The earliest data associating radiation and heart disease originated from studies of long-term patient outcomes after radiotherapy treatment for malignant cancers $(3,30)$. In these types of treatments, the local radiation doses to some regions of the heart can exceed 40 Gy (31), which results in cardiac damage and different pathologies, primarily fibrosis of the pericardium and myocardium (32). Radiation-related myocardial fibrosis is often asymptomatic and diagnosed relatively late (33). It is characterized by a proliferation of fibroblasts and FMT, which involves the activation of fibroblasts and a transition to $\alpha$-SMA-expressing myofibroblasts, which produce an excessive amount of ECM, leading to tissue fibrosis (34). The results of the present study revealed that radiation-induced fibroblasts proliferate and undergo FMT.

MSCs exhibited great potential in treating cardiac damages, even without any pre-treatment. In the 2009, Hare et al provided pivotal safety and provisional efficacy data for an allogeneic bone marrow-derived stem cell without any treatment within post-infarction patients (35). It has been theorized that MSCs reduce cardiac fibrosis largely through paracrine 
A
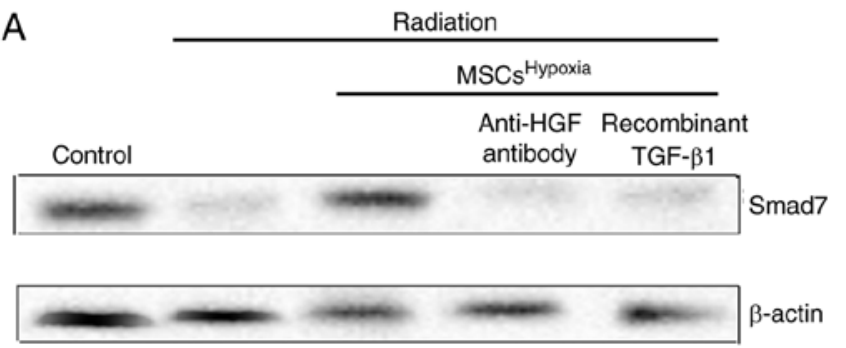

C

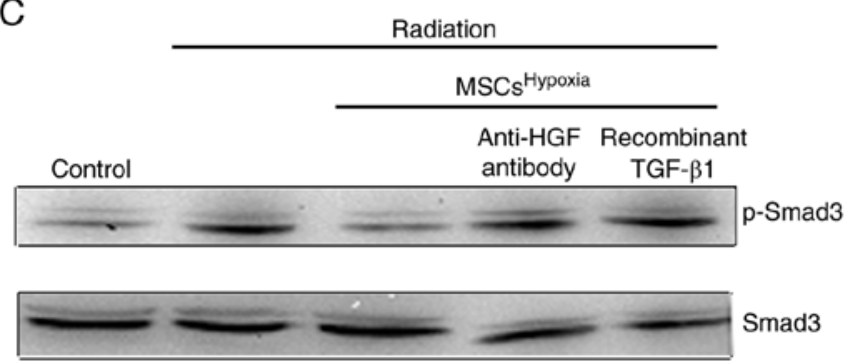

$\mathrm{E}$

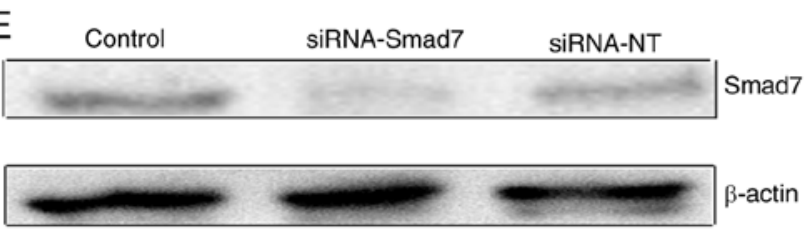

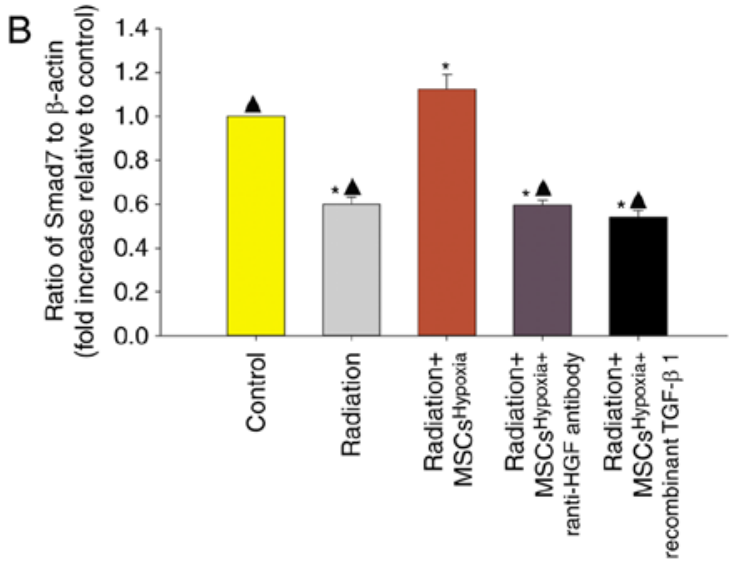
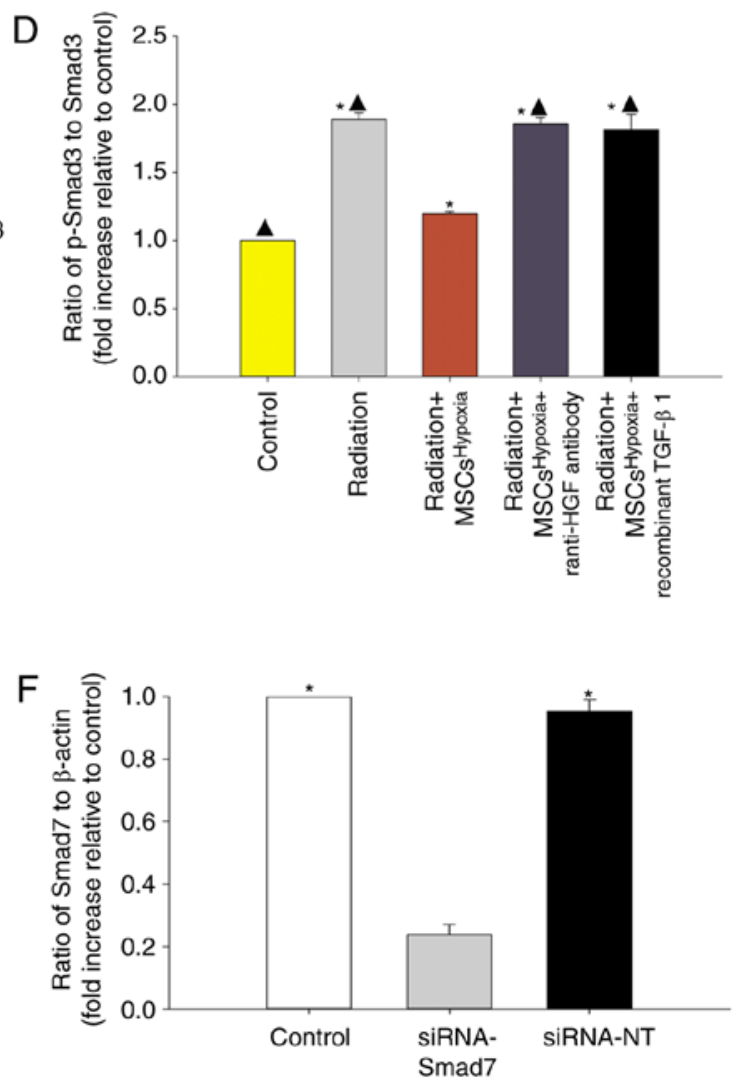

Figure 4. Co-culture with MSCs ${ }^{\text {Hypoxia }}$ induces modulation of the TGF- $\beta 1 /$ Smad signaling pathway. Representative images of western blots of (A and B) Smad7 and $\beta$-actin expression and (C and D) p-Smad3 and Smad3 from fibroblasts, fibroblasts treated with radiation, and fibroblasts co-cultured with MSCs ${ }^{\text {Hypoxia }}$ or MSCs $^{\text {Hypoxia }}+$ anti-HGF antibody or recombinant TGF- $\beta 1$. Each column represents the mean \pm SD from three independent experiments; ${ }^{*} \mathrm{P}<0.05$ vs. the Control; $\triangle \mathrm{P}<0.05$ vs. Radiation + MSCs ${ }^{\text {Hypoxia }}$. (E and F) Fibroblasts were transfected with siRNA-Smad7, or with siRNA-NT as a control. siRNA-mediated transfection efficiency was determined by western blotting. Each column represents the mean \pm SD from three independent experiments; ${ }^{P}<0.05$ vs. siRNA-Smad7. MSCs, mesenchymal stem cells; HGF, hepatocyte growth factor.

signaling mechanisms $(36,37)$, such as via the inhibition of the TGF- $\beta$-induced transformation of fibroblast cells into myofibroblasts, which protects against cardiac damage (38). Hypoxia pre-conditioned MSCs have been revealed to have an increase in paracrine signaling (39), which increases protection against irradiation-induced damage (40). In the present study, it was revealed that co-culturing with $\mathrm{MSCs}^{\text {Hypoxia }}$ inhibited the proliferation of fibroblasts and inhibited their radiation-induced transformation into myofibroblasts via paracrine signaling, in an HGF-dependent manner. It was also revealed that the addition of anti-HGF antibody diminished the anti-fibrotic effect of MSCs ${ }^{\text {Hypoxia }}$, confirming the important role of paracrine HGF signaling in limiting radiation-related fibrosis.

Enhanced levels of TGF- $\beta 1$ are involved in radiation-induced cardiac fibrosis, a condition characterized by excess fibroblast proliferation and a deposition of collagen fibers (41). In line with these observations, the present study revealed a significant increase in TGF- $\beta 1$ expression induced by radiation, while $\mathrm{MSCs}^{\text {Hypoxia }}$ inhibited the expression of TGF- $\beta 1$. The activation of TGF- $\beta$ has been predicted using both transcriptomics and proteomic data sets (15). TGF- $\beta$ signaling is able to initiate the canonical SMAD transduction pathway, leading to fibrosis (42). Smad7, an inhibitory Smad, inhibits 

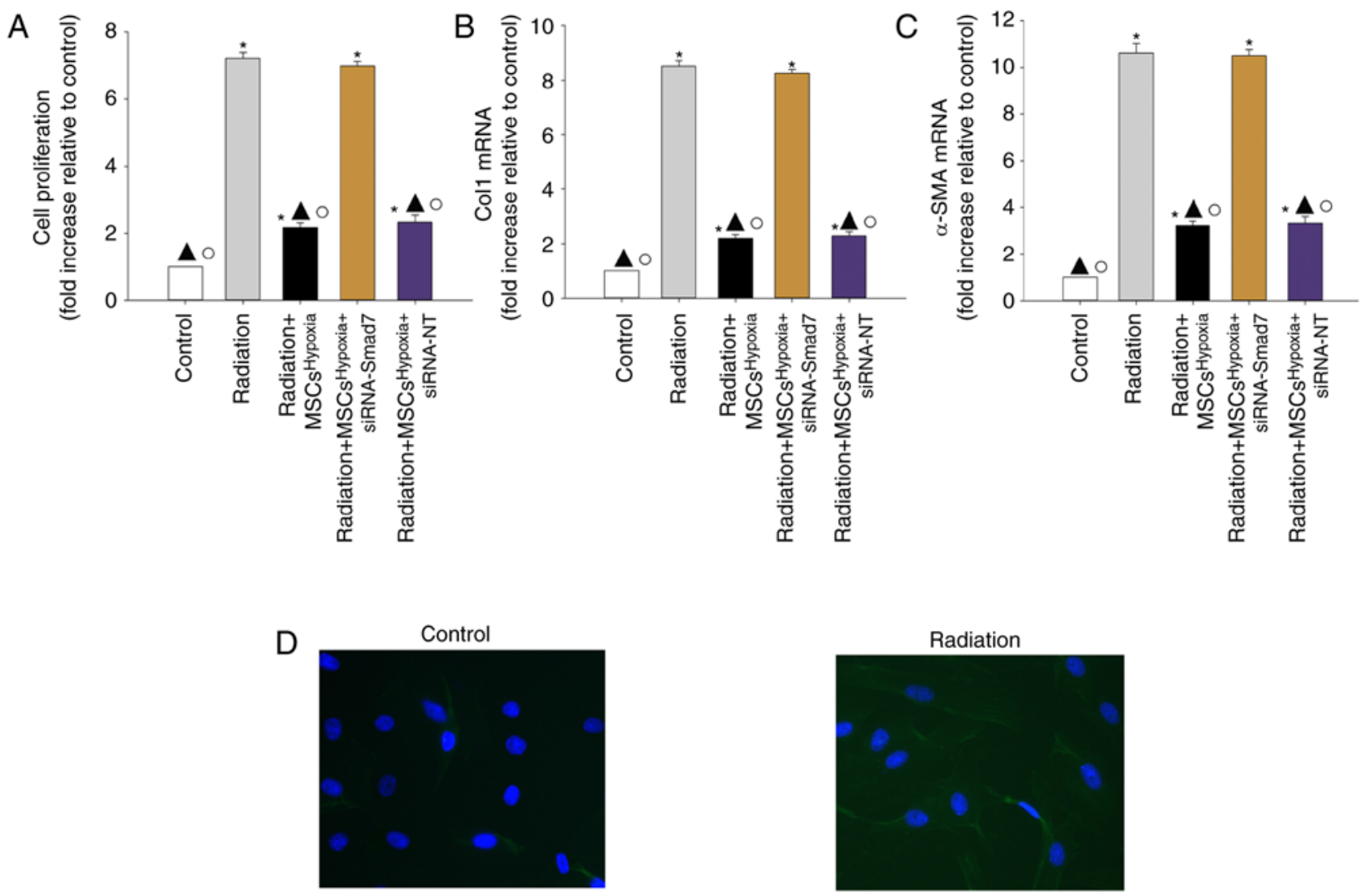

Radiation
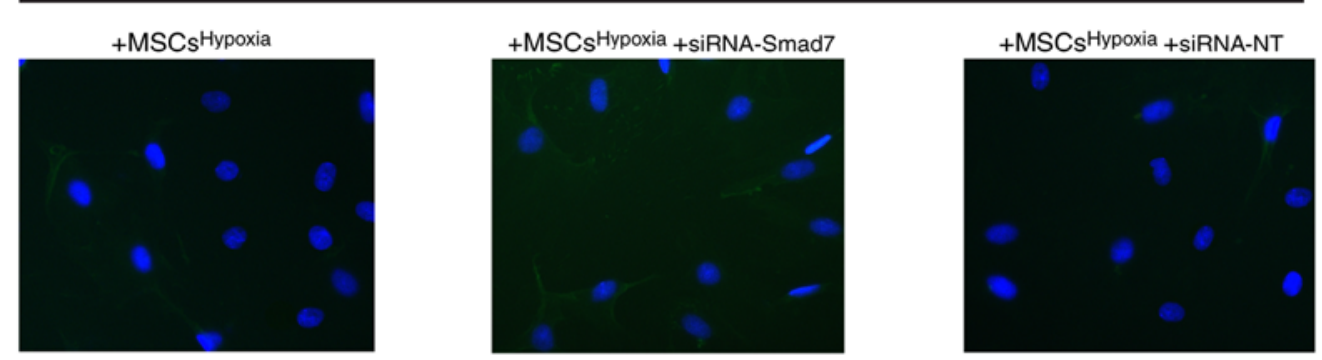

Figure 5. Co-culturing with MSCs ${ }^{\text {Hypoxia }}$ functionally targets Smads downstream of TGF- $\beta 1$ to reduce fibroblast proliferation and FMT. Fibroblasts were transfected with siRNA against Smad7, or with siRNA-NT as a control, followed by co-culture with MSCs ${ }^{\text {Hypoxia }}$ in the presence of radiation. In parallel experiments, fibroblasts were treated with radiation, or co-cultured with MSCs ${ }^{\text {Hypoxia }}$ in the presence of radiation. Fibroblasts under normal culture conditions were used as the control. (A) Proliferation growth curves as determined using an MTT assay. (B and C) Col1 and $\alpha$-SMA mRNA levels as analyzed by RT-qPCR (D) Expression of $\alpha$-SMA as measured by immunofluorescence staining. Each column represents the mean \pm SD from three independent experiments; ${ }^{*} \mathrm{P}<0.05$ vs. the Control; ${ }^{\mathbf{A}} \mathrm{P}<0.05$ vs. Radiation; ${ }^{\circ} \mathrm{P}<0.05$ vs. Radiation $+\mathrm{MSCs}^{\text {Hypoxia }}+$ siRNA-Smad7. MSCs, mesenchymal stem cells; FMT, fibroblast-to-myofibroblast transition; Col1, type I collagen; $\alpha$-SMA, $\alpha$-smooth muscle actin.

the activation of Smad 2 and $\operatorname{Smad} 3$ in response to TGF- $\beta$ activation. Herein, it was demonstrated that co-culturing with MSCs $^{\text {Hypoxia }}$ induced the expression of Smad7, which was inhibited by radiation, while impairing the radiation-induced phosphorylation of Smad3, indicating that the TGF- $\beta / \mathrm{Smad}$ pathway acts to modulate MSC inhibition of radiation-induced fibrosis.

Previous studies have proposed many complex molecular events which lead to the development of radiation-induced cardiac damage (43). Among all these events, radiation-induced oxidative stress and the associated inflammatory responses are likely the key signaling cascades leading to cardiac damage $(44,45)$. Radiation leads to a significant reduction in the levels of antioxidant enzymes such as SOD, and an increase in 4-HNE adducts, which leads to cardiac fibrosis (46). Radiation-induced ROS generation activates MDA and promotes 4-HNE generation, which is accompanied by an inhibition of SOD. The present results revealed that MSC $^{\text {Hypoxia }}$ treatment was able to attenuate oxidative stress. In addition, treatment with anti-HGF antibody, recombinant TGF- $\beta 1$ or siRNA-Smad7 abolished the antioxidant effect of

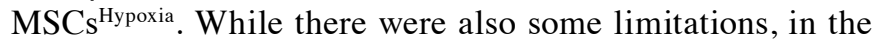
following research, in future, whether hypoxia precondition improves the treatment effect of MSCs in radiation-induced cardiac fibrosis in vivo will be investigated.

In conclusion, in the present study, it was revealed that radiation-induced fibroblast proliferation and FMT were attenuated by co-culturing with MSCs ${ }^{\text {Hypoxia }}$. In addition, 
A

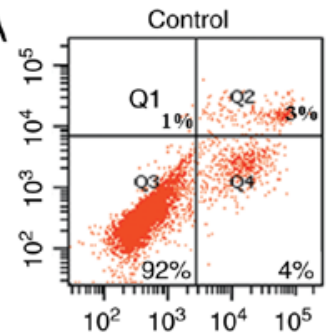

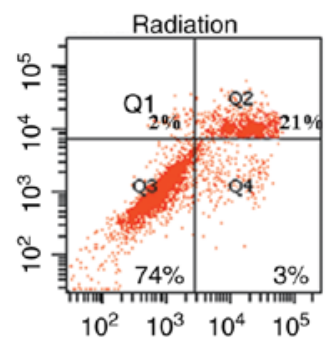

adiation+MSCHyoxia
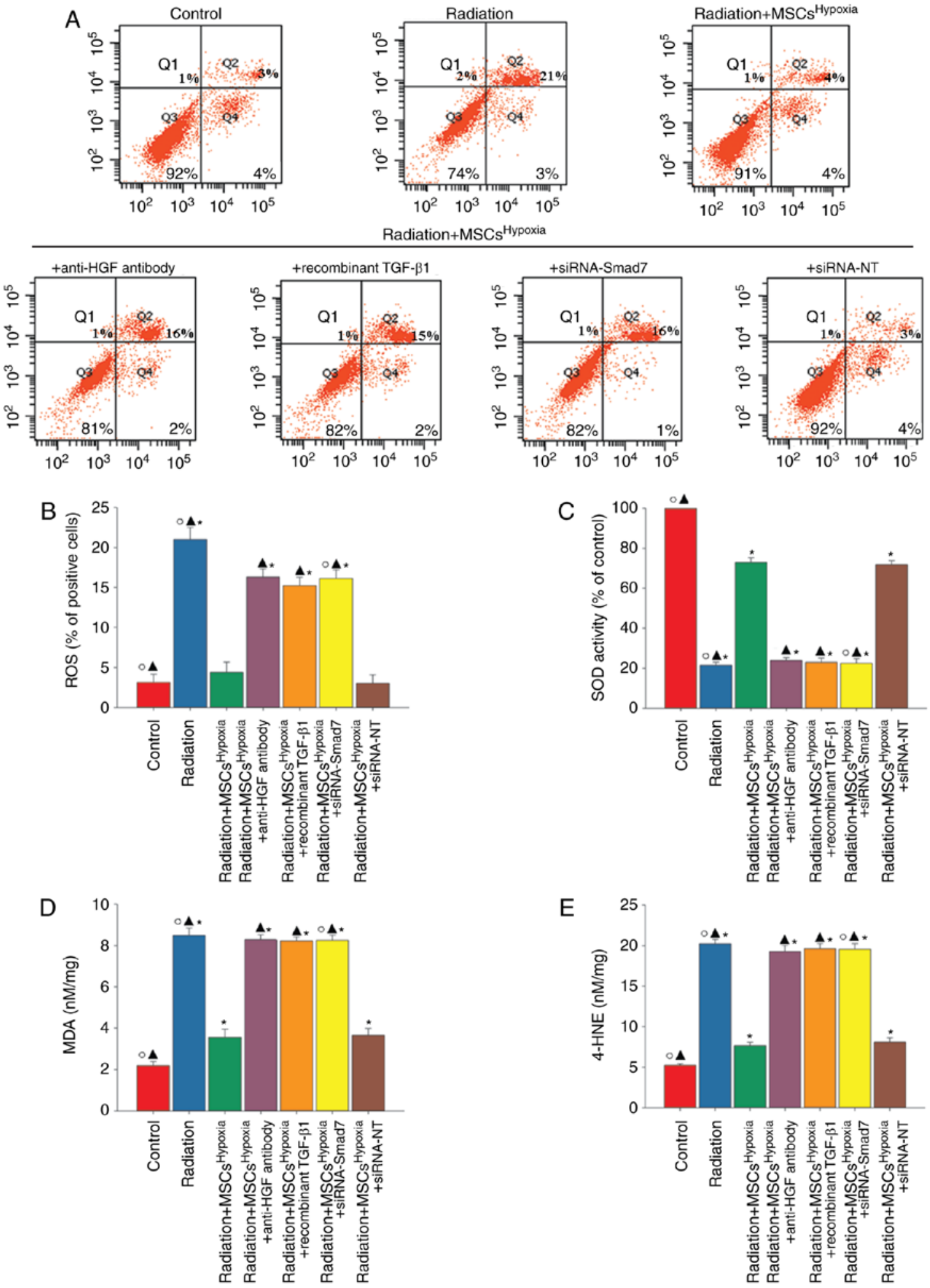

Figure 6. MSC ${ }^{\text {Hypoxia }}$ co-culturing attenuates radiation-induced oxidative stress in fibroblasts. Fibroblasts were transfected with siRNA against Smad7, or with siRNA-NT as a control, followed by co-culture with MSCs ${ }^{\text {Hypoxia }}$ in the presence of radiation. In parallel experiments, fibroblasts were treated with radiation, or co-cultured with MSCs ${ }^{\text {Hypoxia }}$ or MSCs ${ }^{\text {Hypoxia }}+$ anti-HGF antibody or MSCs ${ }^{\text {Hypoxia }}+$ recombinant TGF- $\beta 1$ in the presence of radiation. Fibroblasts under normal culture conditions were used as the control. (A and B) Intracellular ROS production was assessed using a ROS detection kit, and was analyzed using flow cytometry. (C) SOD activity evaluated by a colorimetric assay. (D) Lipid peroxidation as evaluated by MDA formation. (E) Quantification of 4-HNE levels. ${ }^{*} \mathrm{P}<0.05$ vs. the Control; ${ }^{\wedge} \mathrm{P}<0.05$ vs. Radiation $+\mathrm{MSCs}^{\text {Hypoxia }}{ }^{\circ} \mathrm{P}<0.05$ vs. Radiation + MSCs ${ }^{\text {Hypoxia }}+$ siRNA-Smad7. MSCs, mesenchymal stem cells; HGF, hepatocyte growth factor; ROS, reactive oxygen species; SOD, superoxide dismutase; MDA, malondialdehyde; HNE, 4-hydroxynonenal.

the results revealed that $\mathrm{MSCs}^{\text {Hypoxia }}$ exert anti-fibrotic and radio-protective effects by regulating the $\mathrm{TGF}-\beta / \mathrm{Smad}$ signaling pathway, and inhibiting oxidative stress via paracrine pathways. The present study provides evidence that MSCs may be a promising candidate for the treatment of radiation-related cardiac fibrosis. 


\section{Acknowledgements}

Not applicable.

\section{Funding}

The present study was supported by the National Natural Science Foundation of China (grant nos. 81600278 to WX and 81500261 to $\mathrm{MH}$ ) and the Medical Science and Technology Project of Zhejiang Province (grant no. 2018KY517 to MH).

\section{Availability of data and materials}

The data used to support the findings of this study are included within the article.

\section{Authors' contributions}

LZ and WX made substantial contributions to the acquisition of data, analysis and interpretation of data. MH was involved in conception and design of the study, and drafting the manuscript. All authors read and approved the manuscript and agree to be accountable for all aspects of the research in ensuring that the accuracy or integrity of any part of the work are appropriately investigated and resolved.

\section{Ethics approval and consent to participate}

Not applicable.

\section{Patient consent for publication}

Not applicable.

\section{Competing interests}

The authors declare that they have no competing interests.

\section{References}

1. Swerdlow AJ,Higgins CD, Smith P,Cunningham D, Hancock BW, Horwich A, Hoskin PJ, Lister A, Radford JA, Rohatiner AZ and Linch DC: Myocardial infarction mortality risk after treatment for Hodgkin disease: A collaborative British cohort study. J Natl Cancer Inst 99: 206-214, 2007.

2. Darby SC, Ewertz M, McGale P, Bennet AM, Blom-Goldman U, Brønnum D, Correa C, Cutter D, Gagliardi G, Gigante B, et al: Risk of ischemic heart disease in women after radiotherapy for breast cancer. N Engl J Med 368: 987-998, 2013.

3. Darby S, McGale P, Peto R, Granath F, Hall P and Ekbom A Mortality from cardiovascular disease more than 10 years after radiotherapy for breast cancer: Nationwide cohort study of 90000 Swedish women. BMJ 326: 256-257, 2003.

4. Tukenova M, Guibout C, Oberlin O, Doyon F, Mousannif A, Haddy N, Guérin S, Pacquement H, Aouba A, Hawkins M, et al: Role of cancer treatment in long-term overall and cardiovascular mortality after childhood cancer. J Clin Oncol 28: 1308-1315, 2010.

5. Tapio S: Pathology and biology of radiation-induced cardiac disease. J Radiat Res 57: 439-448, 2016.

6. Subramanian V, Borchard S, Azimzadeh O, Sievert W, Merl-Pham J, Mancuso M, Pasquali E, Multhoff G, Popper B, Zischka $\mathrm{H}$, et al: PPAR $\alpha$ is necessary for radiation-induced activation of noncanonical TGF $\beta$ signaling in the heart. J Proteome Res 17: 1677-1689, 2018.

7. Curigliano G, Cardinale D, Dent S, Criscitiello C, Aseyev O, Lenihan D and Cipolla CM: Cardiotoxicity of anticancer treatments: Epidemiology, detection, and management. CA Cancer J Clin 66: 309-325, 2016.
8. Bagno L, Hatzistergos KE, Balkan W and Hare JM: Mesenchymal stem cell-based therapy for cardiovascular disease: Progress and challenges. Mol Ther 26: 1610-1623, 2018.

9. Golpanian S, Wolf A, Hatzistergos KE and Hare JM: Rebuilding the damaged heart: Mesenchymal stem cells, cell-based therapy, and engineered heart tissue. Physiol Rev 96: 1127-1168, 2016.

10. Ma S, Xie N, Li W, Yuan B, Shi Y and Wang Y: Immunobiology of mesenchymal stem cells. Cell Death Differ 21: 216-225, 2014

11. Le Blanc K and Mougiakakos D: Multipotent mesenchymal stromal cells and the innate immune system. Nat Rev Immunol 12: 383-396, 2012.

12. Wu T, Xie Y, Huang J, Li P, Wang X, Yan Y, Xia T, Li L, Zhu F, $\mathrm{Li} \mathrm{H}$ and Wu R: The optimal intervention time of bone marrow mesenchymal stem cells in ameliorating cardiac fibrosis induced by viral myocarditis: A randomized controlled trial in mice. Stem Cells Int 2017: 3258035, 2017.

13. Huang L, Ma W, Ma Y, Feng D, Chen H and Cai B: Exosomes in mesenchymal stem cells, a new therapeutic strategy for cardiovascular diseases? Int J Biol Sci 11: 238-245, 2015.

14. Meng SS, Xu XP, Chang W, Lu ZH, Huang LL, Xu JY, Liu L, Qiu HB, Yang Y and Guo FM: LincRNA-p21 promotes mesenchymal stem cell migration capacity and survival through hypoxic preconditioning. Stem Cell Res Ther 9: 280, 2018.

15. Dobaczewski M, Chen W and Frangogiannis NG: Transforming growth factor (TGF) $-\beta$ signaling in cardiac remodeling. J Mol Cell Cardiol 51: 600-606, 2011

16. Yamamura Y, Hua X, Bergelson S and Lodish HF: Critical role of Smads and AP-1 complex in transforming growth factor-beta-dependent apoptosis. J Biol Chem 275: 36295-36302, 2000.

17. Hayashi H, Abdollah S, Qiu Y, Cai J, Xu YY, Grinnell BW, Richardson MA, Topper JN, Gimbrone MA Jr, Wrana JL and Falb D: The MAD-related protein Smad7 associates with the TGF $\beta$ receptor and functions as an antagonist of TGFbeta signaling. Cell 89: 1165-1173, 1997.

18. Wei LH, Huang XR, Zhang Y, Li YQ, Chen HY, Yan BP, Yu CM and Lan HY: Smad7 inhibits angiotensin II-induced hypertensive cardiac remodelling. Cardiovasc Res 99: 665-673, 2013.

19. Berk BC, Fujiwara K and Lehoux S: ECM remodeling in hypertensive heart disease. J Clin Invest 117: 568-575, 2007.

20. Fredj S, Bescond J, Louault C and Potreau D: Interactions between cardiac cells enhance cardiomyocyte hypertrophy and increase fibroblast proliferation. J Cell Physiol 202: 891-899, 2005.

21. Lucas JA, Zhang Y, Li P, Gong K, Miller AP, Hassan E, Hage F, Xing D, Wells B, Oparil S and Chen YF: Inhibition of transforming growth factor-beta signaling induces left ventricular dilation and dysfunction in the pressure-overloaded heart. Am J Physiol Heart Circ Physiol 298: H424-H432, 2010.

22. Cheema AK, Pathak R, Zandkarimi F, Kaur P, Alkhalil L, Singh R, Zhong X, Ghosh S, Aykin-Burns N and Hauer-Jensen M: Liver metabolomics reveals increased oxidative stress and fibrogenic potential in gfrp transgenic mice in response to ionizing radiation. J Proteome Res 13: 3065-3074, 2014.

23. Yin TC, Wu RW, Sheu JJ, Sung PH, Chen KH, Chiang JY, Hsueh SK, Chung WJ, Lin PY, Hsu SL, et al: Combined therapy with extracorporeal shock wave and adipose-derived mesenchymal stem cells remarkably improved acute ischemia-reperfusion injury of quadriceps muscle. Oxid Med Cell Longev 2018: 6012636, 2018.

24. Moon J, Schwarz SC, Lee HS, Kang JM, Lee YE, Kim B, Sung MY, Höglinger G, Wegner F, Kim JS, et al: Preclinical analysis of fetal human mesencephalic neural progenitor cell lines: Characterization and safety in vitro and in vivo. Stem Cells Transl Med 6: 576-588, 2017.

25. Livak KJ and Schmittgen TD: Analysis of relative gene expression data using real-time quantitative PCR and the 2(-Delta Delta C(T)) method. Methods 25: 402-408, 2001.

26. Teekakirikul P, Eminaga S, Toka O, Alcalai R, Wang L, Wakimoto H, Nayor M, Konno T, Gorham JM, Wolf CM, et al: Cardiac fibrosis in mice with hypertrophic cardiomyopathy is mediated by non-myocyte proliferation and requires Tgf- $\beta$. J Clin Invest 120: 3520-3529, 2010.

27. Zhang Q, Ye H, Xiang F, Song LJ, Zhou LL, Cai PC, Zhang JC Yu F, Shi HZ, Su Y, et al: miR-18a-5p inhibits sub-pleural pulmonary fibrosis by targeting TGF- $\beta$ receptor II. Mol Ther 25 : 728-738, 2017.

28. Ruart M, Chavarria L, Campreciós G, Suárez-Herrera N, Montironi C, Guixé-Muntet S, Bosch J, Friedman SL, GarciaPagán JC and Hernández-Gea V: Impaired endothelial autophagy promotes liver fibrosis by aggravating the oxidative stress response during acute liver injury. J Hepatol 70: 458-469, 2019. 
29. Serrano NA, Mikkelsen R, Canada J, Mezzaroma E, Weiss E and Abbate A: Biomarkers of cardiac injury in patients undergoing thoracic radiation therapy. Int J Cardiol 223: 507-509, 2016.

30. Hancock SL, Donaldson SS and Hoppe RT: Cardiac disease following treatment of Hodgkin's disease in children and adolescents. J Clin Oncol 11: 1208-1215, 1993.

31. McGale P and Darby SC: Low doses of ionizing radiation and circulatory diseases: A systematic review of the published epidemiological evidence. Radiat Res 163: 247-257, 2005.

32. Demirci S, Nam J, Hubbs JL, Nguyen T and Marks LB: Radiation-induced cardiac toxicity after therapy for breast cancer: Interaction between treatment era and follow-up duration. Int J Radiat Oncol Biol Phys 73: 980-987, 2009.

33. Heidenreich PA, Hancock SL, Lee BK, Mariscal CS and Schnittger I: Asymptomatic cardiac disease following mediastinal irradiation. J Am Coll Cardiol 42: 743-749, 2003.

34. Gabbiani G: The myofibroblast in wound healing and fibrocontractive diseases. J Pathol 200: 500-503, 2003.

35. Hare JM, Traverse JH, Henry TD, Dib N, Strumpf RK, Schulman SP, Gerstenblith G, DeMaria AN, Denktas AE, Gammon RS, et al: A randomized, double-blind, placebocontrolled, dose-escalation study of intravenous adult human mesenchymal stem cells (prochymal) after acute myocardial infarction. J Am Coll Cardiol 54: 2277-2286, 2009.

36. Ranganath S, Levy O, Inamdar M and Karp JM: Harnessing the mesenchymal stem cell secretome for the treatment of cardiovascular disease. Cell Stem Cell 10: 244-258, 2012.

37. Molina EJ, Palma J, Gupta D, Torres D, Gaughan JP, Houser S and Macha M: Reverse remodeling is associated with changes in extracellular matrix proteases and tissue inhibitors after mesenchymal stem cell (MSC) treatment of pressure overload hypertrophy. J Tissue Eng Regen Med 3: 85-91, 2009.

38. Shao L, Zhang Y, Lan B, Wang J, Zhang Z, Zhang L, Xiao P, Meng Q, Geng YJ, Yu XY and Li Y: MiRNA-sequence indicates that mesenchymal stem cells and exosomes have similar mechanism to enhance cardiac repair. Biomed Res Int 2017: 4150705, 2017.

39. Hu X, Xu Y, Zhong Z, Wu Y, Zhao J, Wang Y, Cheng H, Kong M, Zhang F, Chen Q, et al: A large-scale investigation of hypoxia-preconditioned allogeneic mesenchymal stem cells for myocardial repair in nonhuman primates: Paracrine activity without remuscularization. Circ Res 118: 970-983, 2016.
40. Shin HS, Lee S, Kim YM and Lim JY: Hypoxia-activated adipose mesenchymal stem cells prevents irradiation-induced salivary hypofunction by enhanced paracrine effect through fibroblast growth factor 10. Stem Cells 36: 1020-1032, 2018.

41. Seemann I, Gabriels K, Visser NL, Hoving S, te Poele JA, Pol JF, Gijbels MJ, Janssen BJ, van Leeuwen FW, Daemen MJ, et al: Irradiation induced modest changes in murine cardiac function despite progressive structural damage to the myocardium and microvasculature. Radiother Oncol 103: 143-150, 2012.

42. Derynck R and Zhang YE: Smad-dependent and Smadindependent pathways in TGF-beta family signalling. Nature 425: 577-584, 2003.

43. Taylor C, Mcgale P, Brønnum D, Correa C, Cutter D, Duane FK, Gigante B, Jensen MB,Lorenzen E, Rahimi K, et al: Cardiac structure injury after radiotherapy for breast cancer: Cross-sectional study with individual patient data. J Clin Oncol 36: 2288-2296, 2018.

44. Hirshfeld JW Jr, Fiorilli PN and Silvestry FE: Important strategies to reduce occupational radiation exposure in the cardiac catheterization laboratory: No lower limit. J Am Coll Cardiol 71: $1255-1258,2018$.

45. Viczenczova C, Kura B, Egan Benova T, Yin C, Kukreja RC, Slezak J, Tribulova N and Szeiffova Bacova B: Irradiation-induced cardiac connexin-43 and miR-21 responses are hampered by treatment with atorvastatin and aspirin. Int J Mol Sci 19, 2018.

46. Seawright JW, Samman Y, Sridharan V, Mao XW, Cao M, Singh P, Melnyk S, Koturbash I, Nelson GA, Hauer-Jensen M and Boerma M: Effects of low-dose rate $\gamma$-irradiation combined with simulated microgravity on markers of oxidative stress, DNA methylation potential, and remodeling in the mouse heart. PLoS One 12: e0180594, 2017.

This work is licensed under a Creative Commons Attribution-NonCommercial-NoDerivatives 4.0 International (CC BY-NC-ND 4.0) License. 